NOAA

\author{
Abstract-Visual surveys of seafloor \\ communities in deep water are be- \\ coming more common and provide \\ fishery-independent abundance esti- \\ mates that could improve stock as- \\ sessments for some groundfish spe- \\ cies. However, limitations of the sur- \\ vey vehicle must be considered when \\ developing methods. To that end, we \\ estimated densities of demersal fish- \\ es from 28 paired strip-transect sur- \\ veys, using a manned submersible (a \\ human-occupied vehicle, HOV) and a \\ remotely operated vehicle (ROV) in \\ 3 types of habitats (high-relief rock, \\ low-relief mixed rock, and soft sedi- \\ ments) at water depths of 75-315 \\ $\mathrm{m}$ off central California. Differenc- \\ Thomas E. Laidig (contact author) \\ Mary M. Yoklavich \\ Email address for contact author: tom.laidig@noaa.gov \\ Southwest Fisheries Science Center \\ National Marine Fisheries Service, NOAA \\ 110 Shaffer Road \\ Santa Cruz, California 95060
} es in fish detection, identification, and measurements were observed between vehicles (e.g., densities of unidentified fishes, unidentified rockfishes, and unidentified species of Sebastomus were significantly higher in ROV surveys). Species most closely associated with the seafloor were observed at higher densities in HOV surveys than in ROV surveys - a result possibly due to the greater reactions of fish to the ROV. The percentage of fish for which we could not estimate size was greater from video images collected with the ROV than from in situ observations made from the HOV. Results of our study will be useful for evaluation of the limitations and biases of these survey vehicles in assessments of demersal fishes.

Manuscript submitted 8 October 2015 . Manuscript accepted 16 June 2016. Fish. Bull. 114:386-396 (2016). Online publication date: 12 July 2016. doi: 10.7755/FB.114.4.2

The views and opinions expressed or implied in this article are those of the author (or authors) and do not necessarily reflect the position of the National Marine Fisheries Service, NOAA.
Visual surveys of seafloor communities in deep water (depths $>50 \mathrm{~m}$ ) are becoming more common, and the results are used to provide fisheryindependent estimates of abundance and to improve stock assessments for some demersal fish species. All survey vehicles are associated with assumptions, biases, and limitations, which must be considered when selecting the type of vehicle and developing a survey design. Biases in underwater visual surveys can result from the influence of illumination, noise, and movement of a vehicle on fish behavior (Stoner et al., 2008). Changes in fish behavior caused by these influences can affect the sampling efficiency of survey vehicles, thereby leading to over- or underestimation of fish abundance.

Various types of vehicles have been used to conduct visual surveys of demersal fish abundance in both trawlable and untrawlable habitats. Adams et al. (1995) used a relatively large remotely operated vehicle (ROV) to estimate population size of several groundfish species on soft sediments, and Krieger (1993) and Krieger and Sigler (1996) estimated density of rockfishes (Sebastes spp.) surveyed with a bottom trawl and a human-occupied vehicle (HOV), also

\title{
A comparison of density and length of Pacific groundfishes observed from 2 survey vehicles: a manned submersible and a remotely operated vehicle
}

known as a manned submersible, in low-relief habitats. Abundance of rockfishes that live in high-relief rock habitats has been determined by using an HOV (O'Connell and Carlile, 1993; Yoklavich et al., 2007), an ROV (Stierhoff et al., 2013), and a combination of hydroacoustics and observations from an ROV (Demer, 2012) as well as by using an ROV, towed stereo-camera sled, and catch composition from a bottom trawl (Jones et al., 2012).

The capabilities and limitations of visual survey vehicles need to be considered when interpreting information obtained from them for management purposes. Estimates of fish abundance from different visual survey vehicles have been compared in only a few studies. O'Connell and Carlile (1994) conducted surveys in Alaska, using an $\mathrm{HOV}$ and a MiniROVER MKI ${ }^{1}$ ROV (Teledyne Benthos, North Falmouth, MA); however, the ROV was effective only in low-relief areas and not useful for quantitatively surveying their target

\footnotetext{
${ }^{1}$ Mention of trade names or commercial companies is for identification purposes only and does not imply endorsement by the National Marine Fisheries Service, NOAA.
} 
species, the yelloweye rockfish (Sebastes ruberrimus) in its primary habitat of high-relief rock. Uzmann et al. (1977) used a towed camera sled (TCS) and HOV to estimate fish densities on Georges Bank. Higher densities of flounders, hakes, and dogfish were found in the HOV surveys, and density of goosefish was greater in the TCS surveys. Cailliet et al. (1999) used a TCS and an HOV to characterize fish species from 3 areas off California and found that species observed in deep surveys were similar between type of vehicle, but 4 species were observed from the HOV that were not seen from the TCS at shallower depths $(<2200 \mathrm{~m})$. More rockfish species were identified by using an ROV then by using a TCS in Alaska (Rooper et al., 2012); however, a larger number of the measurements of fish length were estimated with the stereo cameras on the TCS than with a single camera with paired lasers on the ROV. Understanding the limitations of survey vehicles in providing accurate species detection, identification, and length measurements can help to design effective surveys with a consideration of the specific capabilities of the vehicle and to improve abundance and biomass assessments of the target species.

In this study, we evaluated habitat-specific capabilities of 2 visual survey vehicles (i.e., an HOV and an ROV) to detect, identify, and determine the length of a variety of demersal fishes. Fish density was estimated by using each vehicle in 3 different types of seafloor habitats: high-relief hard rock, lowrelief mixed rock, and soft sediments. In an earlier study, we examined the reactions of fishes to these same vehicles (Laidig et al., 2013), concluding that avoidance reactions to the ROV were greater than those to the HOV and that avoidance of both vehicles was greater by fishes above the seafloor than by fishes on the seafloor. Surveying fishes that display large avoidance reactions to either vehicle could result in inaccurate estimates of density. Here we expand our work to consider the differences in fish densities in relation to reactions of the fish to each vehicle. Information from this study, and that from our previously published work, can be used to evaluate potential limitations and biases of these underwater vehicles and will be useful in developing sampling strategies for surveying demersal fishes.

\section{Materials and methods}

Fish surveys were conducted off the coast of central California, from Monterey Bay to south of Carmel Bay (Fig. 1), with a 2-person HOV and an ROV. Sampling was conducted in the fall of 2007 at depths ranging

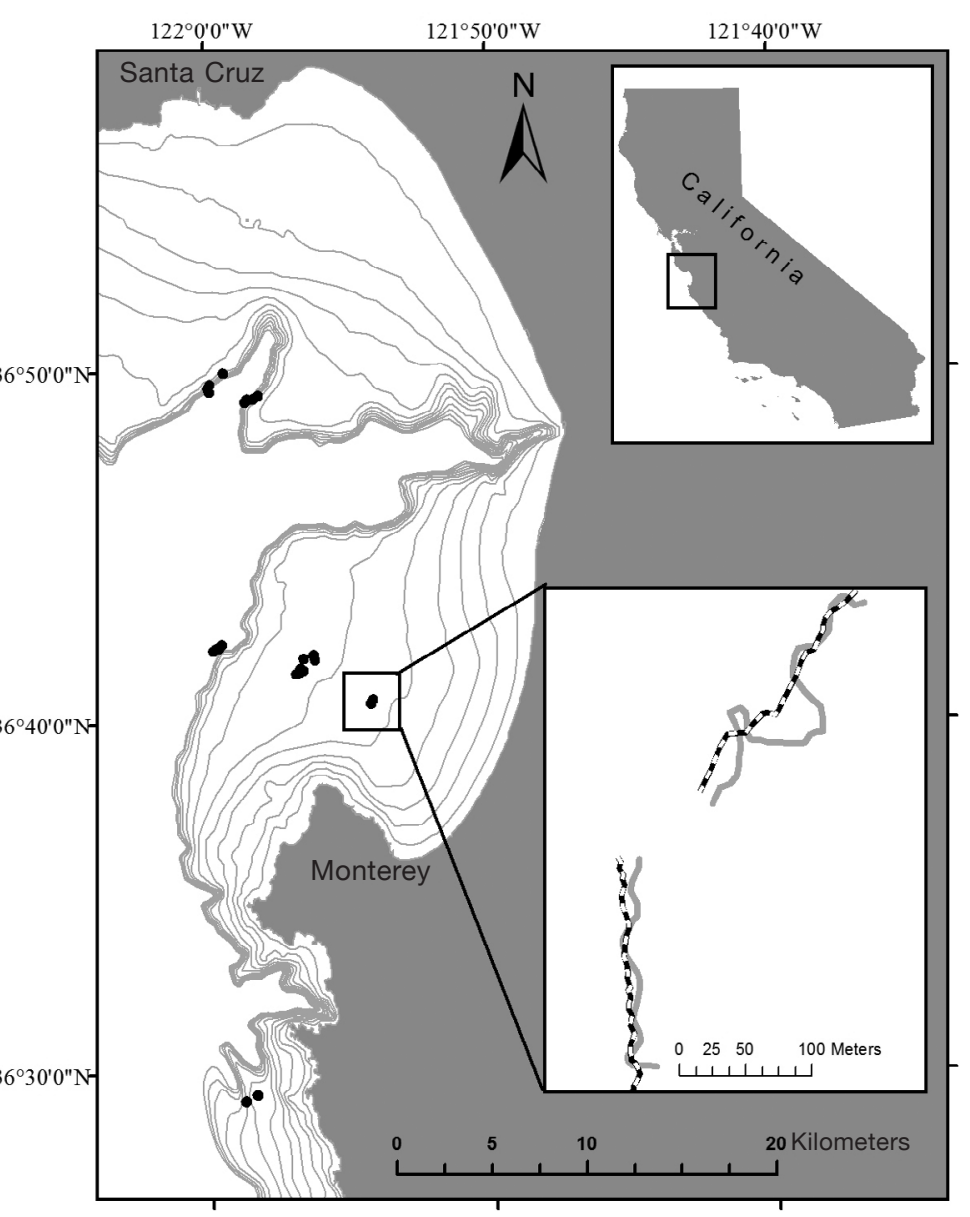

Figure 1

Location of 28 paired transects of surveys conducted with a human-occupied vehicle and a remotely operated vehicle to survey groundfishes off central California in 2007. Bottom inset is an enlargement of 2 sets of paired transects; the dark dashed line represents the HOV track and the light solid line is the ROV track.

from 75 to $315 \mathrm{~m}$ for both vehicles. Sampling took place from 12 October through 4 November for the HOV and from 18 November through 23 November for the ROV. All surveys were conducted during daylight hours (0800-1700), when our species of interest are known to be active (Love et al., 2002).

The 2-person Delta HOV was launched from the FV Velero IV and was operated by experienced pilots from Delta Oceanographics (Torrance, CA). An experienced scientific observer accompanied 1 pilot inside the untethered HOV. The yellow-orange HOV measured 1.8 $\mathrm{m}$ tall, $4.6 \mathrm{~m}$ long, and from $0.4 \mathrm{~m}$ wide at its forwardmost point to $1.1 \mathrm{~m}$ wide at mid-vehicle. A single 24volt motor and propeller provided thrust. An external color video camera (custom-built by DeepSea Power and Light, San Diego, CA), with 400 lines of resolution and an illumination range of 2-100,000 lux, was mounted on the starboard side above the observer's viewport. The HOV was equipped with ten 150 -watt halogen lights, 4 of which were used during surveys (1 
forward light by which the pilot navigated and 3 that illuminated the starboard-side survey area). Two parallel lasers were mounted $20 \mathrm{~cm}$ apart on either side of the camera.

The position of the HOV was tracked from the support vessel with WinFrog integrated navigation software (Fugro Pelagos, San Diego, CA) and an ORE Trackpoint II ultra-short baseline (USBL) acoustic tracking system (EdgeTech, West Wareham, MA). The distance traveled was estimated with a MiniRLG2 measurement unit based on ring laser gyro technology (Teledyne CDL, Houston, TX) and a NavQuest 600 Micro Doppler Velocity Log (DVL; LinkQuest Inc., San Diego, CA) mounted externally on the HOV.

An unmanned Phantom DS4 ROV (Deep Ocean Engineering Inc., San Jose, CA) was operated by experienced pilots from the Southwest Fisheries Science Center (La Jolla, CA), National Marine Fisheries Service, aboard the NOAA Ship David Starr Jordan. The ROV had a yellow body and black frame and measured $1 \mathrm{~m}$ tall, $2 \mathrm{~m}$ long, and $1.4 \mathrm{~m}$ wide. Six electric thrusters (2 angled and 4 that were perpendicular to the seafloor) provided propulsion for the ROV. The ROV was equipped with a forward-facing, color video camera with 470 lines of horizontal resolution and an $18 \times$ optical zoom (FCB-IX47C, Sony Corp., Tokyo) and a Coolpix 995 digital still camera with 3.2 megapixel resolution and $4 \times$ optical zoom (Nikon Corp., Tokyo). Illumination was provided by 2 forward-facing 250-watt Multi SeaLite halogen lights (DeepSea Power and Light) mounted on the ROV camera tray. Two sets of parallel lasers (20 and $61 \mathrm{~cm}$ apart) and 1 crossing laser were mounted to the front of the ROV and used to determine depth of field. The position of the ROV also was determined with WinFrog software and an ORE Trackpoint II plus USBL tracking system.

Strip-transect surveys were conducted with each vehicle, and the resultant video footage was recorded onto MiniDV (HOV) or DVCAM (ROV) tapes. During 10-min surveys of transects, the HOV traveled along a depth contour at an average speed of $0.5 \mathrm{~m} / \mathrm{s}$ (standard error [SE] 0.04) and an average altitude of $1.1 \mathrm{~m}$ (SE 0.04) above the seafloor. The ROV transect surveys were conducted at an average of $1.2 \mathrm{~m}$ (SE 0.08) above the seafloor and at an average speed of $0.6 \mathrm{~m} / \mathrm{s}(\mathrm{SE}$ 0.03 ), and covered a path comparable to that of the HOV.

During these transect surveys, the observer inside the HOV identified and counted all fish that occurred within $2 \mathrm{~m}$ on the starboard side. The observer also estimated size of fish to the nearest $5 \mathrm{~cm}$ in total length (TL), using the paired lasers. The observer's comments were captured on an audio channel of the video footage for later review.

Video footage collected from the HOV and ROV and digital still images collected from the ROV were reviewed by one person in the laboratory after the surveys. Fish were identified to the lowest possible taxon and counted. Some species were not considered in our analyses. For instance, pelagic schooling fishes, such as the northern anchovy (Engraulis mordax), jack mackerel (Trachurus symmetricus), and Pacific chub mackerel (Scomber japonicus), swam around the vehicles for extended periods of time, increasing the possibility that these fish would be counted more than once. From the ROV images, fish size was estimated to the nearest 5 $\mathrm{cm}$ TL by using the parallel lasers. An effort was made to estimate the size of all fish in both surveys, with the exception of fish in holes, partially obscured by objects, perpendicular to the plane of the laser spots, or in midwater (providing no target for the lasers). We also used the laser spots in the images from the ROV to estimate width of transects. The space between the paired 20$\mathrm{cm}$ lasers (Measured laser width) was measured with a ruler on the video screen once during each minute of a transect survey. Transect width was estimated with the following equation:

$$
\text { Transect width }=\left(\frac{\text { Measured screen width }}{\text { Measured laser width }}\right) \times \text { Laser width, }
$$

where Laser width $=20 \mathrm{~cm}$; and

Measured screen width $=$ the horizontal width of the video screen through the laser spots.

We examined only video footage that was collected while the vehicles were traveling forward in survey mode (i.e., the vehicle was considered to be on transect). Fish were counted when they were observed within 2 $m$ of the starboard side of the HOV (as estimated with a handheld dive sonar inside the HOV) or $2 \mathrm{~m}$ in front of the ROV. Brief stops by the ROV to capture still images for identification of species (at a rate of about 1 image/min) and to avoid obstacles were considered to occur on transect. No fish observations were counted in instances where the seafloor was not seen in the video footage for $>5 \mathrm{~s}$ (for example, when a vehicle transited over small canyons or the ROV was pulled backwards by the ship). Information on identification and size of fish was augmented by comments from the observer inside the HOV, and data from the ROV surveys were derived only from video and still images.

We determined the amount and type of primary and secondary seafloor habitat from the video footage taken along each transect. Primary habitat covered $>50 \%$ of the seafloor, and secondary habitat covered $>20 \%$ of the remaining seafloor. We used 4 main habitat types: bedrock ( $\mathrm{R}$; large in-place rock), boulders ( $\mathrm{B}$; unattached rock $>25 \mathrm{~cm})$, cobble $(\mathrm{C}$; unattached rock $<25 \mathrm{~cm})$, and mud (M). We reduced the 16 habitat combinations to 3 categories: hard was any combination of rock, boulder, and cobble in both the primary and secondary groupings ( $\mathrm{RR}, \mathrm{RB}, \mathrm{RC}, \mathrm{BR}, \mathrm{BB}, \mathrm{BC}, \mathrm{CR}, \mathrm{CB}, \mathrm{CC})$, mixed was a combination of mud as the primary or secondary habitat and one of the other habitat types (MR, MB, MC, RM, BM, CM), and soft was entirely mud (MM). Habitat categories were assigned to patches of distinct substratum types, delineated by time. Length of each patch was then estimated from time-specific cumulative distance (as measured with the DVL [HOV] or USBL [ROV]) along each transect. The areas of all habitat 


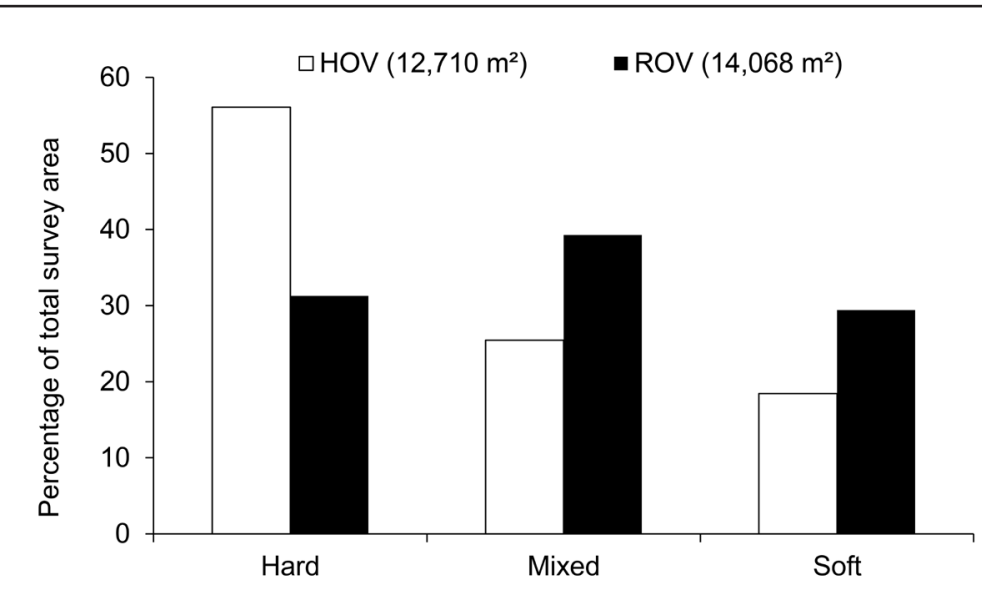

Figure 2

Percentage of survey area classified as hard, mixed, and soft habitat for surveys conducted off central California in 2007 with a human-occupied vehicle (HOV) and a remotely operated vehicle (ROV). Numbers in parentheses are the total area surveyed by each vehicle. differ significantly from normal for these analyses. We used a Tukey-Kramer posthoc test to determine which taxa accounted for significant differences. We used a Kolmogorov-Smirnov 2-sample test to examine differences in length distributions of fishes between vehicles for each habitat. Further, we examined the differences in mean length for each habitat, using a Student's $t$-test.

\section{Results}

We analyzed 28 pairs of transect surveys conducted with the HOV and the ROV. The estimated width of an HOV transect was 2 $\mathrm{m}$, and the average width of an ROV transect was $1.9 \mathrm{~m}$ (SE 0.07). The total survey area (transect width $\times$ total length of all transects) was $12,710 \mathrm{~m}^{2}$ for the $\mathrm{HOV}$ and $14,068 \mathrm{~m}^{2}$ for the ROV. For HOV surveys, hard habitat was the category with the greatest amount of survey area (56\%), followed by mixed and soft habitats (26\% and patches (length $\times$ width) in each habitat category were summed for each transect.

We selected corresponding $\mathrm{HOV}$ and ROV transects for our analyses. We began with a 10-min HOV transect and then matched the corresponding ROV track with the start and end points of the HOV survey using ArcGIS 9.2 (ESRI, Redlands, CA). This approach resulted in transects of similar lengths. We excluded sections from the paired transects that were $>10 \mathrm{~m}$ apart. If sections were discarded, the remaining sections of the survey track were combined for each vehicle to form the sample transect used for analyses. Total area for each of the 3 habitat categories (average transect width $\times$ total length of each habitat category) was estimated per transect. All 3 habitats were not encountered on every transect, and some habitats were present in only small amounts. To further refine comparisons between the HOV and ROV transect surveys, only total areas $>20 \mathrm{~m}^{2}$ for each habitat category on each of the paired transects were considered in the analyses. Using this method, we used 21 of the 28 paired transects for the hard habitat category, 22 transects for the mixed habitat category, and 14 transects for the soft habitat category for our comparisons.

Fish densities were determined for each habitat category (hard, mixed, and soft) within each transect. Density was estimated as the total number of fish of a particular taxon per total area of a habitat category on each transect. A pairwise (by transect) unbalanced analysis of variance (ANOVA), with unequal sample size, was used to compare mean densities (of each fish taxon and of all taxa combined) between the 2 vehicles, among the 3 habitat categories, and to compare interactions between vehicles and habitats. This work was done with the statistical program SAS 9.4 (SAS Institute Inc., Cary, NC). The distribution of residuals did not
$18 \%$, respectively) (Fig. 2). For the ROV, mixed habitat was most abundant category (39\%), and hard and soft habitats were found in similar proportions (31\% and 29 $\%$, respectively) (Fig. 2).

During HOV surveys, 4489 fish were counted, and 6480 fish were counted from the ROV. For the analyses, we included only 23 common taxa (i.e., taxa that accounted for at least $1 \%$ of the total number of fish observed from either the HOV or ROV), which included 4235 fish from the HOV surveys and 6253 from the ROV surveys. Total fish density was not significantly different for the 2 vehicles in surveys of any of the 3 habitat categories: hard (Tukey-Kramer; $P>0.05$ ), mixed (Tukey-Kramer; $P>0.05$ ), and soft (Tukey-Kramer; $P>0.05$ ).

Most fish occupied hard habitat (73\% and $57 \%$ of all fishes observed in the HOV and ROV surveys, respectively; Table 1A). Average density of all fish in hard habitat was 42.1 individuals $/ 100 \mathrm{~m}^{2}$ (HOV) and 53.8 individuals/100 $\mathrm{m}^{2}$ (ROV). The pygmy rockfish (Sebastes wilsoni), the halfbanded rockfish (S. semicinctus), and young-of-the-year (YOY) rockfishes (Sebastes spp., 5 cm TL or less) were the 3 most abundant taxa in the HOV surveys. The most abundant taxa on ROV transects were the pygmy rockfish, the halfbanded rockfish, unidentified rockfishes (Sebastes spp. $>5 \mathrm{~cm}$ TL), and unidentified species of Sebastomus (a subgenus of 11 similar-looking species of rockfishes [Love et al., 2002], 4 members of which are shown in Figure 3). Densities of YOY, rosy ( $S$. rosaceus), and rosethorn ( $S$. helvomaculatus) rockfish in hard habitat were significantly greater on HOV transects than on ROV transects (TukeyKramer: $P<0.05)$. Densities of unidentified rockfishes and unidentified Sebastomus were significantly greater in the ROV surveys than in the HOV surveys (TukeyKramer: $P<0.01$ ). 


\section{Table 1}

The number and mean density of fish taxa or groups observed during visual surveys conducted with a human-occupied vehicle (HOV) and a remotely occupied vehicle (ROV) in 2007 off central California. Data are reported as (A) individual taxa and (B) combined fish groups per habitat category (hard, mixed, and soft). Common names in bold text are considered benthic taxa. Densities are the number of fish per $100 \mathrm{~m}^{2}$. An asterisk $(*)$ indicates significantly greater fish density for that vehicle compared with the other. A superscript ${ }^{1}$ indicates taxa that are in the Sebastomus group. SD=standard deviation; YOY=young-of-the-year; TL=total length.

\begin{tabular}{|c|c|c|c|c|c|c|c|c|c|c|c|}
\hline \multirow[b]{2}{*}{ Common name } & \multirow[b]{2}{*}{ Scientific name } & \multirow[b]{2}{*}{$\begin{array}{l}\text { Total } \\
\text { fish }\end{array}$} & \multicolumn{9}{|c|}{$\mathrm{HOV}$} \\
\hline & & & No. & $\begin{array}{c}\text { Hard } \\
\text { density }\end{array}$ & $\mathrm{SD}$ & No. & $\begin{array}{l}\text { Mixed } \\
\text { density }\end{array}$ & SD & No. & $\begin{array}{c}\text { Soft } \\
\text { density }\end{array}$ & $\mathrm{SD}$ \\
\hline \multicolumn{12}{|l|}{ A Individual taxa } \\
\hline Bank rockfish & Sebastes rufus & 124 & 114 & 1.3 & 5.3 & 8 & 0.3 & 0.7 & 2 & 0.1 & 0.2 \\
\hline Blackeye goby & Rhinogobiops nicholsii & 235 & 119 & 1.9 & 3.9 & 81 & $4.3^{*}$ & 6.6 & 35 & 1.8 & 3.4 \\
\hline Bocaccio & Sebastes paucispinis & 97 & 94 & 1.6 & 5.3 & 3 & 0.2 & 0.7 & 0 & 0.0 & 0.0 \\
\hline Flatfishes & Pleuronectiformes & 108 & 22 & 0.3 & 0.7 & 26 & 0.8 & 1.5 & 60 & 3.0 & 3.0 \\
\hline Greenspotted rockfish $^{1}$ & Sebastes chlorostictus & 89 & 58 & 0.7 & 1.9 & 27 & 1.0 & 1.8 & 4 & 0.2 & 0.3 \\
\hline Greenstriped rockfish & Sebastes elongatus & 47 & 29 & 0.4 & 1.8 & 9 & 0.4 & 1.7 & 9 & 0.5 & 1.3 \\
\hline Hagfishes & Eptatretus spp. & 157 & 3 & 0.0 & 0.1 & 5 & 0.1 & 0.3 & 149 & 4.3 & 15.6 \\
\hline Halfbanded rockfish & Sebastes semicinctus & 779 & 538 & 8.1 & 14.0 & 207 & 4.7 & 8.6 & 34 & 1.8 & 5.3 \\
\hline Pink seaperch & Zalembius rosaceus & 16 & 8 & 0.1 & 0.2 & 6 & 0.3 & 0.6 & 2 & 0.1 & 0.3 \\
\hline Poachers & Agonidae & 77 & 9 & 0.1 & 0.3 & 39 & 0.9 & 1.9 & 29 & 1.6 & 2.2 \\
\hline Pygmy rockfish & Sebastes wilsoni & 971 & 919 & 11.6 & 15.4 & 50 & 1.0 & 2.2 & 2 & 0.1 & 0.2 \\
\hline Rosethorn rockfish $^{1}$ & Sebastes helvomaculatus & 99 & 58 & $0.9^{*}$ & 1.4 & 38 & $0.9^{*}$ & 1.3 & 3 & 0.2 & 0.1 \\
\hline Rosy rockfish $^{1}$ & Sebastes rosaceus & 128 & 111 & $1.7^{*}$ & 2.1 & 15 & $0.6^{*}$ & 0.9 & 2 & 0.1 & 0.6 \\
\hline Splitnose rockfish & Sebastes diploproa & 145 & 43 & 1.8 & 5.6 & 91 & 1.7 & 5.2 & 11 & 0.5 & 1.2 \\
\hline Squarespot rockfish & Sebastes hopkinsi & 171 & 156 & 2.1 & 2.8 & 14 & 0.5 & 1.5 & 1 & 0.0 & 0.1 \\
\hline Starry rockfish $^{1}$ & Sebastes constellatus & 49 & 44 & 0.6 & 1.1 & 5 & 0.2 & 0.5 & 0 & 0.0 & 0.0 \\
\hline Thornyheads & Sebastolobus spp. & 77 & 8 & 0.2 & 0.8 & 43 & 0.8 & 1.6 & 26 & 1.4 & 3.6 \\
\hline Unidentified fishes & Osteichthyes & 24 & 13 & 0.2 & 0.5 & 5 & 0.1 & 0.4 & 6 & 0.6 & 1.6 \\
\hline Unidentified rockfishes & Sebastes spp. & 60 & 44 & 0.5 & 0.6 & 14 & 0.2 & 0.5 & 2 & 0.1 & 0.5 \\
\hline Unidentified Sebastomus ${ }^{1}$ & Sebastes spp. & 101 & 79 & 1.1 & 1.0 & 19 & 0.6 & 0.9 & 3 & 0.2 & 0.5 \\
\hline Widow rockfish & Sebastes entomelas & 73 & 73 & 0.7 & 2.7 & 0 & 0.0 & 0.0 & 0 & 0.0 & 0.0 \\
\hline Yellowtail rockfish & Sebastes flavidus & 79 & 78 & 1.0 & 1.9 & 1 & 0.1 & 0.3 & 0 & 0.0 & 0.0 \\
\hline YOY rockfishes & Sebastes spp. (YOY) & 529 & 473 & $5.2^{*}$ & 9.6 & 34 & 1.7 & 6.3 & 22 & 1.0 & 1.2 \\
\hline Total & & 4235 & 3093 & 42.1 & & 740 & 21.4 & & 402 & 17.6 & \\
\hline \multicolumn{12}{|l|}{ B Combined fish groups } \\
\hline All benthic fish & & 1167 & 540 & 8.0 & 6.6 & 307 & $10.4^{*}$ & 6.9 & 320 & 14.8 & 17.6 \\
\hline All large fish ( $\geq 30 \mathrm{~cm} \mathrm{TL})$ & & 496 & 436 & $5.8^{*}$ & 9.6 & 59 & 1.6 & 2.7 & 1 & 0.0 & 0.1 \\
\hline All Sebastomus & Sebastes spp. & 466 & 350 & 4.7 & 3.4 & 104 & 3.3 & 1.9 & 12 & 0.7 & 0.7 \\
\hline
\end{tabular}

In mixed habitats, 740 fish were observed and counted in the HOV surveys (an average of 21.4 individuals $/ 100 \mathrm{~m}^{2}$ ) and 2208 fish were counted in the ROV surveys (27.5 individuals/100 $\mathrm{m}^{2}$; Table 1A). The halfbanded rockfish was the most abundant taxon identified from each vehicle in mixed habitats (an average of 4.7 individuals $/ 100 \mathrm{~m}^{2}$ on $\mathrm{HOV}$ transects and 11.4 individuals $/ 100 \mathrm{~m}^{2}$ on ROV transects). The densities of blackeye goby (Rhinogobiops nicholsii) and rosethorn and rosy rockfish in mixed habitats were significantly greater in HOV surveys than in ROV surveys (TukeyKramer: $P<0.05$ ). Densities of unidentified fishes (Osteichthyes), unidentified Sebastomus, and unidentified rockfishes were significantly greater on ROV transects than on HOV transects (Tukey-Kramer: $P<0.05$ ).
The lowest density of fish in surveys from both vehicles occurred in soft habitats (17.6 individuals/100 $\mathrm{m}^{2}$ for the HOV surveys and 11.8 individuals $/ 100 \mathrm{~m}^{2}$ for the ROV surveys; Table 1A). Hagfishes (Eptatretus spp., most likely Pacific hagfish [E. stoutii]), flatfishes (Pleuronectiformes), halfbanded rockfish, blackeye goby, and poachers (Agonidae) were relatively abundant in soft habitat on both HOV and ROV surveys. Unidentified Sebastomus was the only group having significantly greater density (Tukey-Kramer: $P<0.05$ ) on the ROV surveys than on HOV surveys over soft habitats.

Densities of rosy rockfish and unidentified rockfish differed significantly between the 2 survey vehicles in the 3 habitat categories (i.e., there was a significant interaction between survey vehicle and habitat; un- 
Table 1 continued

\begin{tabular}{|c|c|c|c|c|c|c|c|c|c|c|c|}
\hline \multirow[b]{2}{*}{ Common name } & \multirow[b]{2}{*}{ Scientific name } & \multirow[b]{2}{*}{$\begin{array}{l}\text { Total } \\
\text { fish }\end{array}$} & \multicolumn{9}{|c|}{ ROV } \\
\hline & & & No. & $\begin{array}{c}\text { Hard } \\
\text { density }\end{array}$ & $\mathrm{SD}$ & No. & $\begin{array}{c}\text { Mixed } \\
\text { density }\end{array}$ & SD & No. & $\begin{array}{c}\text { Soft } \\
\text { density }\end{array}$ & $\mathrm{SD}$ \\
\hline \multicolumn{12}{|l|}{ A Individual taxa } \\
\hline Bank rockfish & Sebastes rufus & 48 & 4 & 0.3 & 1.3 & 42 & 0.7 & 3.3 & 2 & 0.1 & 0.2 \\
\hline Blackeye goby & Rhinogobiops nicholsii & 158 & 42 & 0.8 & 1.3 & 59 & 1.1 & 1.8 & 57 & 1.4 & 2.8 \\
\hline Bocaccio & Sebastes paucispinis & 32 & 28 & 0.7 & 2.5 & 4 & 0.1 & 0.3 & 0 & 0.0 & 0.0 \\
\hline Flatfishes & Pleuronectiformes & 81 & 2 & 0.0 & 0.2 & 14 & 0.4 & 0.6 & 65 & 1.9 & 1.8 \\
\hline Greenspotted rockfish ${ }^{1}$ & Sebastes chlorostictus & 73 & 24 & 0.5 & 0.8 & 37 & 0.8 & 1.3 & 12 & 0.4 & 0.7 \\
\hline Greenstriped rockfish & Sebastes elongatus & 45 & 6 & 0.2 & 0.5 & 23 & 0.3 & 0.8 & 16 & 0.3 & 0.5 \\
\hline Hagfishes & Eptatretus spp. & 44 & 0 & 0.0 & 0.0 & 5 & 0.2 & 0.7 & 39 & 1.0 & 4.9 \\
\hline Halfbanded rockfish & Sebastes semicinctus & 1906 & 729 & 15.2 & 38.7 & 1080 & 11.4 & 24.1 & 97 & 1.0 & 2.1 \\
\hline Pink seaperch & Zalembius rosaceus & 67 & 5 & 0.1 & 0.1 & 57 & 1.3 & 5.6 & 5 & 0.2 & 0.4 \\
\hline Poachers & Agonidae & 72 & 2 & 0.0 & 0.3 & 20 & 0.6 & 1.3 & 50 & 1.3 & 1.6 \\
\hline Pygmy rockfish & Sebastes wilsoni & 2090 & 1928 & 20.8 & 60.0 & 159 & 3.0 & 5.8 & 3 & 0.1 & 0.2 \\
\hline Rosethorn rockfish $^{1}$ & Sebastes helvomaculatus & 12 & 6 & 0.2 & 0.6 & 6 & 0.1 & 0.3 & 0 & 0.0 & 0.0 \\
\hline Rosy rockfish $^{1}$ & Sebastes rosaceus & 42 & 27 & 0.4 & 0.6 & 13 & 0.2 & 0.4 & 2 & 0.1 & 0.2 \\
\hline Splitnose rockfish & Sebastes diploproa & 88 & 11 & 1.0 & 3.9 & 32 & 0.8 & 2.4 & 45 & 1.2 & 4.3 \\
\hline Squarespot rockfish & Sebastes hopkinsi & 104 & 59 & 1.0 & 2.0 & 44 & 0.9 & 3.2 & 1 & 0.0 & 0.1 \\
\hline Starry rockfish ${ }^{1}$ & Sebastes constellatus & 22 & 16 & 0.3 & 0.3 & 6 & 0.1 & 0.3 & 0 & 0.0 & 0.0 \\
\hline Thornyheads & Sebastolobus spp. & 33 & 4 & 0.2 & 0.6 & 16 & 0.4 & 0.9 & 13 & 0.3 & 0.9 \\
\hline Unidentified fishes & Osteichthyes & 195 & 133 & 1.8 & 4.3 & 38 & $0.6^{*}$ & 0.9 & 24 & 0.5 & 0.7 \\
\hline Unidentified rockfishes & Sebastes spp. & 320 & 164 & $3.9 *$ & 3.7 & 102 & $1.8^{*}$ & 2.8 & 54 & 1.1 & 1.9 \\
\hline Unidentified Sebastomus ${ }^{1}$ & Sebastes spp. & 307 & 162 & $3.9 *$ & 4.0 & 122 & $2.1^{*}$ & 2.6 & 23 & $0.8^{*}$ & 1.2 \\
\hline Widow rockfish & Sebastes entomelas & 14 & 14 & 0.3 & 0.6 & 0 & 0.0 & 0.0 & 0 & 0.0 & 0.0 \\
\hline Yellowtail rockfish & Sebastes flavidus & 71 & 55 & 1.0 & 2.0 & 16 & 0.3 & 0.8 & 0 & 0.0 & 0.0 \\
\hline YOY rockfishes & Sebastes spp. (YOY) & 429 & 113 & 1.2 & 4.2 & 313 & 0.3 & 1.2 & 3 & 0.1 & 0.2 \\
\hline Total & & 6253 & 3534 & 53.8 & & 2208 & 27.5 & & 511 & 11.8 & \\
\hline \multicolumn{12}{|l|}{ B Combined fish groups } \\
\hline All benthic fish & & 889 & 291 & 6.4 & 4.2 & 321 & 6.4 & 4.8 & 277 & 7.8 & 5.2 \\
\hline All large fish $(\geq 30 \mathrm{~cm} \mathrm{TL})$ & & 211 & 81 & 1.9 & 2.4 & 94 & 1.7 & 2.1 & 36 & 1.0 & 1.9 \\
\hline All Sebastomus & Sebastes spp. & 456 & 235 & 5.0 & 4.3 & 184 & 3.4 & 3.4 & 37 & 1.1 & 1.6 \\
\hline
\end{tabular}

balanced ANOVA: $P<0.05)$. The interaction effect was based on the observations of greater densities in the HOV surveys for rosy rockfish and in the ROV surveys for unidentified rockfish in both hard and mixed habitats and based on the observations of low densities of each of these taxa in soft sediments in surveys conducted with both vehicles. There was no significant interaction among vehicles and habitat types in our comparisons of densities of the other taxa.

We grouped taxa typically occurring on the seafloor (Love et al., 2002; Love, 2011) into a category called benthic fish (bolded common names in Table 1A). We grouped them in this way because, in a related study, we found that fishes living on the seafloor reacted least to both vehicles than fishes that occurred above the seafloor (Laidig et al., 2013). Benthic fish represented 25\% of the total number of fish observed in the HOV survey and about $14 \%$ of all fish seen in the ROV survey (Table 1B). Densities of benthic fish were similar for both the vehicles in surveys of hard and soft habitats, but there were significantly more benthic fish in mixed habitat in the HOV survey (Tukey-Kramer: $P<0.01$ ).
We grouped the 4 identified species of Sebastomus (i.e., the greenspotted [S. chlorostictus], starry [S. constellatus], rosethorn, and rosy rockfish) with the unidentified Sebastomus to investigate the degree of difficulty in identification of these similar-looking species (Fig. 3). Densities for the category "all Sebastomus" were not significantly different from densities for any of the 3 habitat categories in either the $\mathrm{HOV}$ or ROV surveys (Table 1B).

Most fish in the HOV and ROV surveys were small ( $\leq 15 \mathrm{~cm}$ TL), a size group that represented about $73 \%$ of all fish with length estimates observed from the HOV (3027 of 4146 fish) and $85 \%$ of fish seen from the ROV (4706 of 5537 fish; Fig. 4). The most abundant groups with fish $\leq 15 \mathrm{~cm}$ TL in surveys from both vehicles were pygmy, halfbanded, and YOY rockfishes. Pygmy rockfish accounted for $70 \%$ of the 5 -cm-TL fish and $51 \%$ of $10-\mathrm{cm}-\mathrm{TL}$ fish from the ROV transects but for only $26 \%$ of 5 -cm-TL fish and $40 \%$ of $10-\mathrm{cm}$-TL fish from the HOV transects. Most small fish were observed in hard habitats $(79 \%$ and $62 \%$ of all fish with length estimates on $\mathrm{HOV}$ and $\mathrm{ROV}$ transects, respectively). 


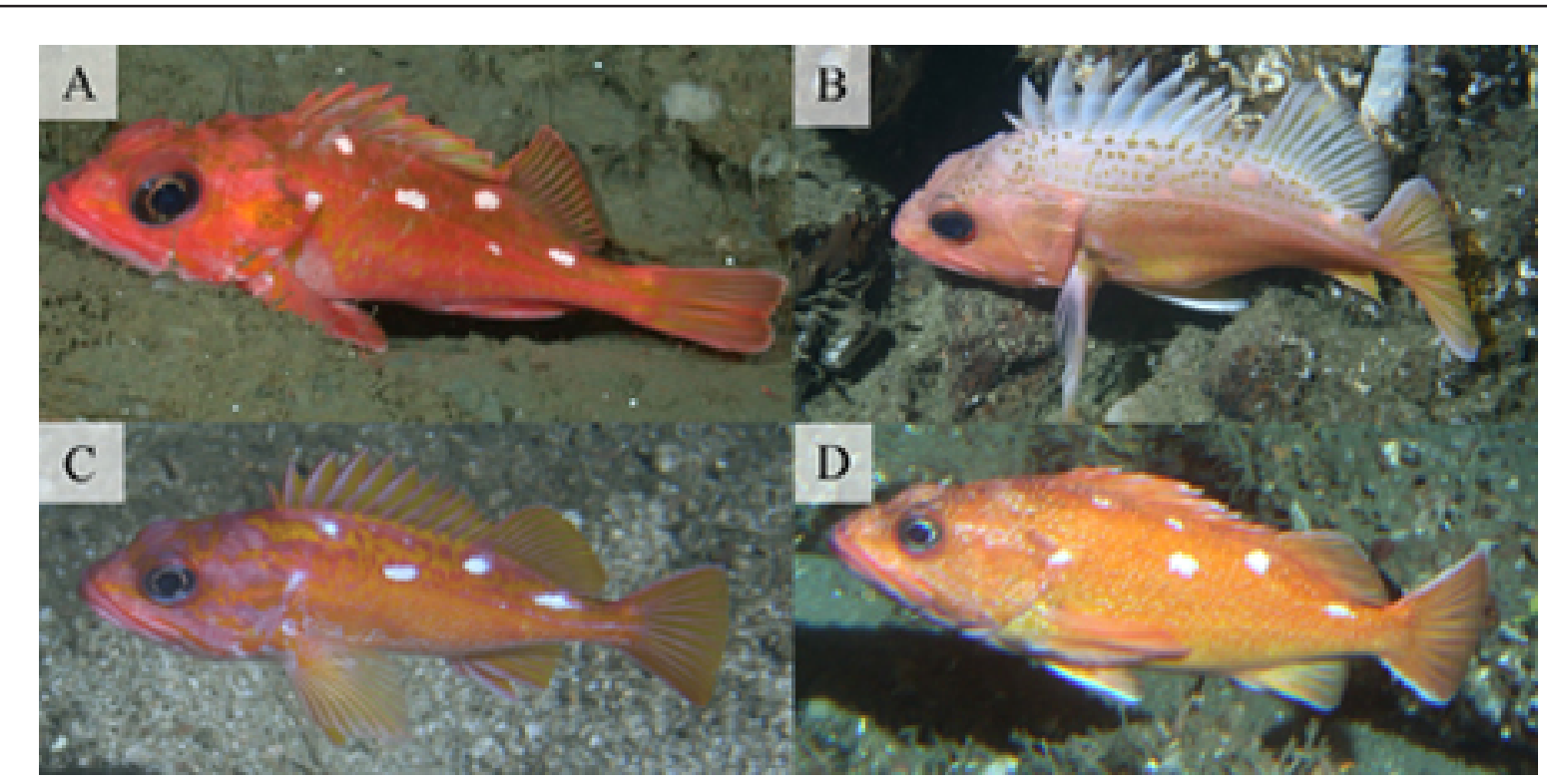

Figure 3

Underwater images of 4 similar-looking species of rockfish in the subgenus Sebastomus: (A) rosethorn rockfish (Sebastes helvomaculatus) identified by green pigmentation along dorsal surface (photograph by J. Butler); (B) greenspotted rockfish (S. chlorostictus), identified by green spots along the dorsal surface (photograph by J. Field); (C) rosy rockfish (S. rosaceus), identified by purple on the head (photograph by L. Snook); and (D) starry rockfish ( $S$. constellatus), identified by the numerous tiny white speckles on the body (photograph by R. Starr).

The lowest number of small fish (mostly blackeye goby and halfbanded rockfish) occurred on soft sediments (5\% of all fish with length estimates on both HOV and ROV transects).

The group called large fish $(\geq 30 \mathrm{~cm}$ TL) accounted for $12 \%$ and $4 \%$ of all fish observed from the HOV and the ROV (Table 1B). Bocaccio (Sebastes paucispinis; $n=97$ ), as well as bank ( $S$. rufus; $n=108)$, yellowtail ( $S$. flavidus; $n=67$ ), and widow ( $S$. entomelas; $n=63$ ) rockfish were abundant large fish in the HOV surveys, and the most abundant large fish in the ROV surveys were unidentified Sebastomus $(n=54)$, as well as yellowtail $(n=47)$, greenspotted $(n=34)$, and splitnose (Sebastes diploproa; $n=29$ ) rockfish. The density of large fish in hard habitats was 3 times greater on $\mathrm{HOV}$ transects than on ROV transects (Tukey-Kramer: $P<0.05$ ).

Fish length could not be estimated for 89 fish representing 10 taxa ( $2 \%$ of all fish) in the HOV surveys and for 716 fish in 22 taxa (11\% of all fish) in the ROV surveys (Table 2). The most abundant taxa among fish of unknown size in the HOV surveys were hagfishes $(n=56)$, unidentified rockfishes $(n=11)$, and unidentified Sebastomus $(n=7)$. For the ROV surveys, the most abundant taxa without size estimates were unidentified rockfishes ( $n=191)$, halfbanded rockfish $(n=180)$, and unidentified Sebastomus $(n=70)$. The greatest percentage of fish without size estimates was from surveys with both vehicles in soft habitat (14\% of fish from the HOV surveys and $23 \%$ of fish from the ROV surveys). This finding was mainly a result of hagfishes that could not be measured because they were observed in partial view (i.e., in holes or under rocks). However, disregarding hagfishes, lengths of $15 \%$ of other fish in soft habitats (e.g., unidentified rockfishes and other fish species, and halfbanded rockfish hovering above the seafloor) could not be estimated from the ROV images compared with $<1 \%$ of fish from the HOV surveys. Length distributions of fish were significantly different for both vehicles for each habitat category (Kolmogorov-Smirnov test: $P<0.005)$. The $\mathrm{HOV}$ and ROV surveys yielded a different average fish size for hard habitats (Student's $t$-test: $P<0.03 ; 17.0 \mathrm{~cm}$ TL for HOV transects and $18.0 \mathrm{~cm}$ TL for ROV transects) and for soft habitats (Student's $t$-test: $P<0.005 ; 15.1 \mathrm{~cm}$ TL for HOV surveys and $16.7 \mathrm{~cm}$ TL for ROV surveys) but average fish size was not significantly different for mixed habitats $(16.4 \mathrm{~cm}$ TL for HOV transects and $17.0 \mathrm{~cm}$ TL for ROV transects).

\section{Discussion}

The ability to accurately identify fishes is a necessity when conducting meaningful visual surveys underwater. Without the fish in hand, some taxa are difficult to identify to species (e.g., 11 similar-looking Sebastomus rockfishes co-occur on the central California coast) and others are practically impossible to discern (e.g., the small cryptic species of poachers [particularly the 4 species of the deep-dwelling genus Xeneretmus]). Densi- 


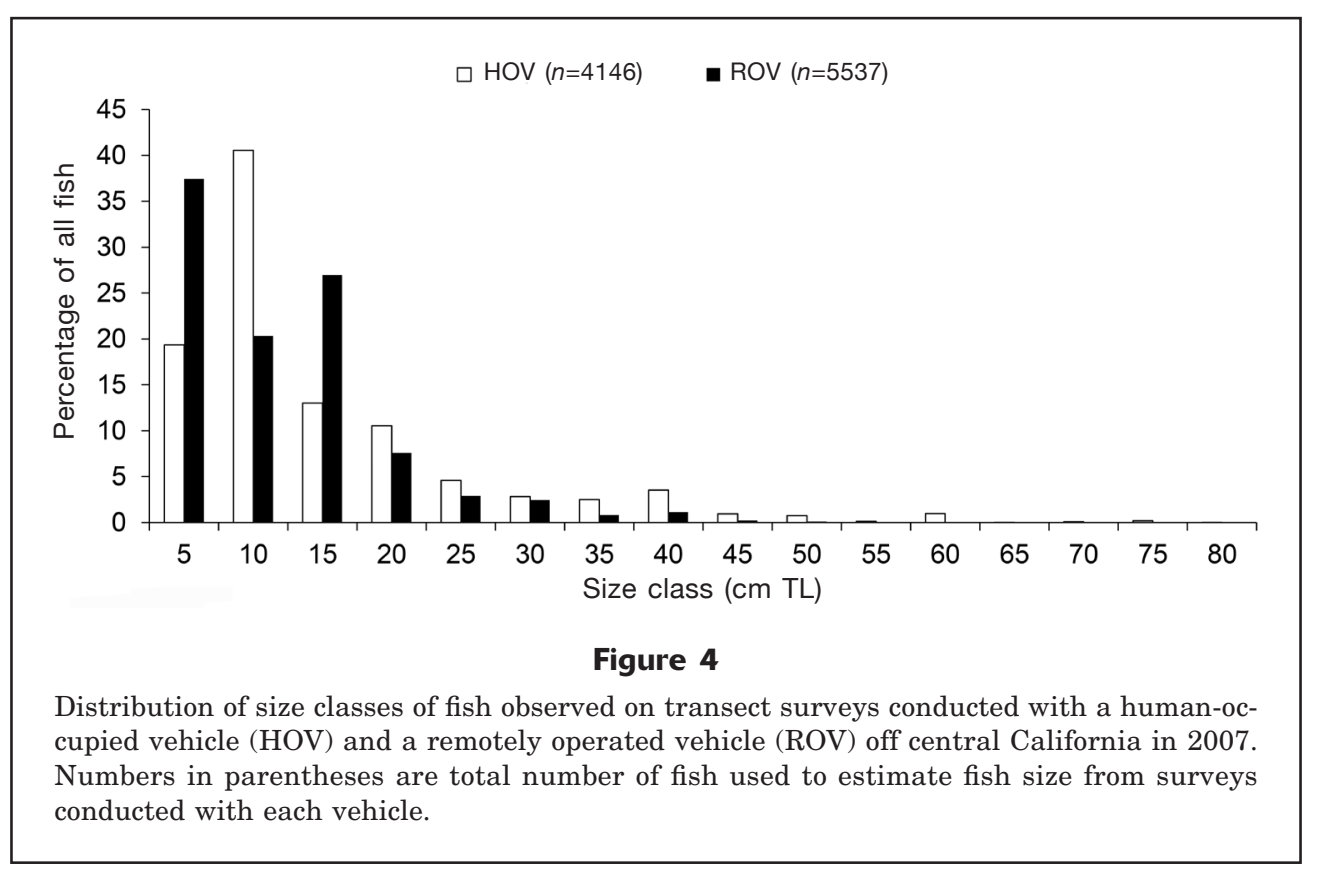

ties of unidentified rockfishes, unidentified Sebastomus, and unidentified fishes were all significantly greater in the ROV surveys than in the HOV surveys. In a study off southern California with the use of the same ROV as that used in this study (Demer, 2012), 12\% of all rockfishes could not be identified to species. Rockfishes also were difficult to identify by using an ROV off British Columbia (8\% unidentified; Du Preez and Tunnicliffe, 2011) and Alaska (9\% unidentified; Rooper et al., 2012), areas where there are far fewer species of rockfishes than off the central California coast (Love et al., 2002). Our ability to identify species from video images should improve with the availability of advanced camera technology (e.g., light-field cameras in which an array of lenses can collect information, such as distance to, and size of, targets) and increased video resolution (moving from high definition with 1440 lines of resolution to ultra-high definition with $2000,4000,8000$, or 16,000 lines).

Nonetheless, not all fish can be identified to species by observers inside an HOV. Unidentified rockfish (not including YOY rockfishes) varied from $<1 \%$ to $4 \%$ of all fish observed by using HOVs in benthic surveys off Oregon and California (Pearcy et al., 1989; Stein et al., 1992; Yoklavich et al., 2002); unidentified rockfishes accounted for $5 \%$ of all fishes in the HOV surveys in our study. Although HOV surveys have relatively low numbers of unidentified rockfishes, identification to species can be extremely difficult, no matter what visual survey vehicle is used, in areas of high rockfish diversity and high numbers of small individuals. For example, Love et al. (2009) counted more than 700,000 fish from a minimum of 137 species (with at least 50 Sebastes species) using an HOV off southern California. Because of the high diversity and small size of the fish (over 60\% of fish were $<15 \mathrm{~cm}$ TL) in that region, many rockfish could not be identified to species (unidentified rockfish and unidentified Sebastomus composed $15 \%$ and $3 \%$ of all fish, respectively).

Our ability to accurately estimate the length of fish was limited when the ROV was used. In particular, without a reference surface, lasers on the ROV were not helpful as a measurement tool for fish that hovered or swam above the seafloor and for fish that were oriented perpendicular to the laser spots. Rochet et al. (2006) examined accuracy of lasers to measure fish and concluded that the major difficulty in measuring fish lengths was caused by the orientation and position of fish. Measuring fish with laser arrays also has proved problematic in other ROV surveys (Johnson et al., 2003; Rooper et al., 2012). However, the increasing use of stereo camera systems on visual survey vehicles is improving the accuracy of underwater measurements of fish, including fish in the water column that cannot be measured by using lasers alone. In a study of rockfishes in Alaska, researchers were able to measure $35 \%$ of all fish by using a towed stereo-camera sled, compared with $10 \%$ of the fish observed from an ROV with paired lasers and a single camera (Rooper et al., 2012).

The presence of an in situ observer, whether in an HOV in deep water or with scuba at shallow depths, is more effective than using only video footage when detecting, identifying, and measuring fish species. The in situ observer in an HOV has a 3-dimensional view and a wider depth of field than the depth of the view from a 2-dimensional video monitor. The in situ view allows the observer to distinguish a cryptic fish from the background more easily than a fish in the same background seen in a video image. As the HOV passes an area, the observer can look in multiple directions in contrast to 


\section{Table 2}

Number of all fish observed, number of unmeasured fishes observed, and proportion of all observed fish that were unmeasured from surveys of groundfish conducted over hard, mixed, and soft habitats with a human-occupied vehicle (HOV) and a remotely operated vehicle (ROV) off central California in 2007.

\begin{tabular}{|c|c|c|c|c|c|c|c|c|}
\hline & \multicolumn{4}{|c|}{$\mathrm{HOV}$} & \multicolumn{4}{|c|}{ ROV } \\
\hline & All habitats & Hard & Mixed & Soft & All habitats & Hard & Mixed & Soft \\
\hline Total unmeasured & 89 & 23 & 10 & 56 & 716 & 283 & 315 & 118 \\
\hline Total fish & 4235 & 3093 & 740 & 402 & 6253 & 3534 & 2208 & 511 \\
\hline Proportion unmeasured (\%) & 2 & 1 & 1 & 14 & 11 & 8 & 14 & 23 \\
\hline
\end{tabular}

the single, fixed direction of a video camera. This practice creates greater opportunity to detect and identify fishes within the transect area. For example, Marliave and Challenger (2009) conducted paired strip-transect surveys with scuba off British Columbia, in which one diver surveyed by eye and the other used a video camera. They found that fish counts per dive hour estimated in situ by the divers (i.e., by eye) were as much as double the counts estimated per dive hour from the diver's video footage. They attributed this difference to the ability of divers to survey in multiple directions (forward, left, and right) and thereby could detect fish more easily within the transect area. Further, Stein et al. (1992) and O'Connell and Carlile (1994) suggested that video and still images were not as effective as the human eye for accurate fish identifications.

Estimating size of fish also can be improved with an in situ observer in the water (by using either scuba or an HOV). Length of fish in midwater is nearly impossible to estimate from a video image, but a human can use natural stereo vision and the laser reference dots to help estimate size. In our study, lengths were unknown for only $2 \%$ of fish in the HOV surveys, compared with $11 \%$ in the ROV surveys. Advances in video technology have increased the ability to detect, identify, and estimate the size of fish. Interestingly, most of these advances, including stereo cameras with increased field of view and high definition in 3-dimensional space, imitate attributes of the human eye.

Difficulty in species identification and fish measurement during ROV surveys occurred in all habitat types, indicating that these issues are not habitat specific. When using the ROV, we were less able to identify or estimate the size of fish on soft sediment than we were in mixed or hard rock habitats. However, the greater number of fish of unknown size is partially the result of hagfishes viewed in holes. Other studies in which fish densities have been compared between vehicles have focused effort on a single seafloor habitat type, such as mud (Uzmann et al., 1977; Krieger, 1993; Adams et al., 1995) or rocky outcrops (O'Connell and Carlile, 1994). Our study is unique in its comparison of fish densities estimated by using an HOV and ROV in 3 different habitats.
Small fish, in particular, can be difficult to detect and identify with visual survey vehicles. In a study in which fish abundance near 3 gas platforms was estimated with an ROV and compared with fish abundance estimated by scuba divers, Andaloro et al. (2013) found that 9 taxa of small benthic species were reported in the diver surveys but none of those taxa were observed with the ROV. Small rockfishes $<20 \mathrm{~cm}$ TL could not be identified to species during nearshore ROV surveys in the waters of southeast Alaska (Johnson et al., 2003), and Love et al. (2009) suggested that densities of small fish taxa, such as the bluebanded goby (Lythrypnus dalli), could be underestimated in their HOV surveys. In our study, densities of small benthic fishes (such as blackeye goby, poachers, hagfishes, and YOY rockfishes) were greater from HOV surveys than from ROV surveys in all habitats. This difference is also reflected in the significantly smaller sizes of fishes in HOV surveys conducted over hard and soft habitats, compared with sizes of fishes in ROV surveys. The observer inside the HOV was able to see, identify, and measure many small species that otherwise would have been difficult to detect in video footage alone. Consequently, an ROV may not be the vehicle of choice to assess the importance of nursery grounds, predator-prey interactions, or ecosystem functions, all of which require an ability to detect and identify small fish species.

When selecting a survey vehicle for visual assessments, associated assumptions, biases, and limitations must be considered, along with logistic variables, such as cost and availability of the tools and optimal survey design (Yoklavich et al., 2015). For example, bias in estimating abundance can result from fish avoidance or attraction to particular survey vehicles (Adams et al., 1995; Trenkel et al., 2004; Lorance and Trenkel, 2006). Laidig et al. (2013), using the same HOV and ROV as those used in our study, assessed the reactions of fishes and found that more fishes reacted to the tethered ROV than to the autonomous HOV (57\% versus $11 \%$ avoidance, respectively). They also found that the proportion of fishes residing on the seafloor that reacted negatively to the vehicle was $2 \%$ for the HOV compared with $18 \%$ for the ROV. 
Considering this result, we expected higher fish densities in the HOV surveys. Indeed, blackeyed goby and YOY, rosethorn, and rosy rockfish had significantly higher densities in the HOV surveys, and only the unidentified taxa had significantly higher densities in the ROV surveys. Additionally, benthic species (as a group) had higher densities in the HOV surveys. Results from our study, and those from our companion work on fish reactions (Laidig et al., 2013), indicate that abundance of at least some demersal fish species will be underestimated depending on which vehicle is used for a survey. This type of information improves understanding of the limitations and biases associated with visual survey methods used to identify and count fish species underwater.

\section{Acknowledgments}

We thank R. Starr, a co-principal investigator of the HOV cruise, J. Butler and S. Mau for operating the ROV, the pilots and crew of the Delta HOV, and the crews of the FV Velero $I V$ and the NOAA Ship David Starr Jordan. We thank M. Love, M. Nishimoto, T. O'Connell, L. Krigsman, and D. Watters for help with data collection; D. Watters also assisted with data analysis. We thank C. Rooper and K. Stierhoff for their thoughtful reviews of this manuscript. Underwater images of Sebastomus were taken by J. Butler, J. Field, L. Snook, and R. Starr. This study was funded in part by a grant from the California Ocean Protection Council to R. Starr and M. Yoklavich.

\section{Literature cited}

Adams, P. B., J. L. Butler, C. H. Baxter, T. E. Laidig, K. A. Dahlin, and W. W. Wakefield.

1995. Population estimates of Pacific coast groundfishes from video transects and swept-area trawls. Fish. Bull. 93:446-455.

Andaloro, F., M. Ferraro, E. Mostarda, T. Romeo, and P. Consoli.

2013. Assessing the suitability of a remotely operated vehicle (ROV) to study the fish community associated with offshore gas platforms in the Ionian Sea: a comparative analysis with underwater visual censuses (UVCs). Helgol. Mar. Res. 67:241-250. Article

Cailliet, G. M., A. H. Andrews, W. W. Wakefield, G. Moreno, and K. L. Rhodes.

1999. Fish faunal and habitat analyses using trawls, camera sleds and submersibles in benthic deepsea habitats off central California. Oceanol. Acta 22:579-592. Article

Demer, D. A.

2012. 2007 survey of rockfishes in the Southern California Bight using the collaborative optical-acoustic survey technique. NOAA Tech. Memo. NMFS-SWFSC-498, 110 p.

Du Preez, C., and V. Tunnicliffe.

2011. Shortspine thornyhead and rockfish (Scorpaenidae) distribution in response to substratum, biogenic structures and trawling. Mar. Ecol. Prog. Ser. 425:217231. Article

Johnson, S. W., M. L. Murphy, and D. J. Csepp.

2003. Distribution, habitat, and behavior of rockfishes, Sebastes spp., in nearshore waters of southeastern Alaska: observations from a remotely operated vehicle. Environ. Biol. Fish. 66:259-270. Article

Jones, D. T., C. D. Wilson, A. De Robertis, C. N. Rooper, T. C. Weber, and J. L. Butler.

2012. Evaluation of rockfish abundance in untrawlable habitat: combining acoustic and complementary sampling tools. Fish. Bull. 110:332-343.

Krieger, K. J.

1993. Distribution and abundance of rockfish determined from a submersible and by bottom trawling. Fish. Bull. 91:87-96

Krieger, K. J., and M. F. Sigler.

1996. Catchability coefficient for rockfish estimated from trawl and submersible surveys. Fish. Bull. 94:282-288.

Laidig, T. E., L. M. Krigsman, and M. M. Yoklavich.

2013. Reactions of fishes to two underwater survey tools, a manned submersible and a remotely operated vehicle. Fish. Bull. 111:54-67. Article

Lorance, P., and V. M. Trenkel.

2006. Variability in natural behaviour, and observed reactions to an ROV, by mid-slope fish species. J. Exp. Mar. Biol. Ecol. 332:106-119. Article

Love, M. S., M. Yoklavich, and L. Thorsteinson.

2002. The rockfishes of the northeast Pacific, 405 p. Univ. Calif. Press, Berkeley, CA.

Love, M. S., M. Yoklavich, and D. M. Schroeder.

2009. Demersal fish assemblages in the Southern California Bight based on visual surveys in deep water. Environ. Biol. Fish. 84:55-68. Article

Love, M. S.

2011. Certainly more than you want to know about the fishes of the Pacific coast, 672 p. Really Big Press, Santa Barbara, CA.

Marliave, J., and W. Challenger.

2009. Monitoring and evaluating rockfish conservation areas in British Columbia. Can. J. Fish. Aquat. Sci. 66:995-1006. Article

O'Connell, V. M., and D. W. Carlile.

1993. Habitat-specific density of adult yelloweye rockfish Sebastes ruberrimus in the eastern Gulf of Alaska. Fish. Bull. 91:304-309.

1994. Comparison of a remotely operated vehicle and a submersible for estimating abundance of demersal shelf rockfishes in the eastern Gulf of Alaska. North Am. J. Fish. Manage. 14:196-201. Article

Pearcy, W. G., D. L. Stein, M. A. Hixon, E. K. Pikitch, W. H. Barss, and R. M. Starr.

1989. Submersible observations of deep-reef fishes of Heceta Bank, Oregon. Fish. Bull. 87:955-965.

Rochet, M.-J., J.-F. Cadiou, and V. M. Trenkel.

2006. Precision and accuracy of fish length measurements obtained with two visual underwater methods. Fish. Bull. 104:1-9.

Rooper, C. N., M. H. Martin, J. L. Butler, D. T. Jones, and M. Zimmermann.

2012. Estimating species and size composition of rockfishes to verify targets in acoustic surveys of untrawlable areas. Fish. Bull. 110:317-331. 
Stein, D. L., B. N. Tissot, M. A. Hixon, and W. Barss. 1992. Fish-habitat associations on a deep reef at the edge of the Oregon continental shelf. Fish. Bull. 90:540-551. Stierhoff, K. L., J. L. Butler, S. A. Mau, and D. W. Murfin.

2013. Abundance and biomass estimates of demersal fishes at The Footprint and Piggy Bank from optical surveys using a remotely operated vehicle (ROV). NOAA Tech. Memo. NMFS-SWFSC-521, 45 p.

Stoner, A. W., C. H. Ryer, S. J. Parker, P. J. Auster, and W. W. Wakefield.

2008. Evaluating the role of fish behavior in surveys conducted with underwater vehicles. Can. J. Fish. Aquat. Sci. 65:1230-1243. Article

Trenkel, V. M., R. I. C. C. Francis, P. Lorance, S. Mahévas, M.J. Rochet, and D. M. Tracey.

2004. Availability of deep-water fish to trawling and visual observation from a remotely operated vehicle (ROV). Mar. Ecol. Prog. Ser. 284:293-303. Article
Uzmann, J. R., R. A., Cooper, R. B. Theroux, and R. L. Wigley. 1977. Synoptic comparison of three sampling techniques for estimating abundance and distribution of selected megafauna: submersible vs camera sled vs otter trawl. Mar. Fish. Rev. 39(12):11-19.

Yoklavich, M., G. Cailliet, R. N. Lea, H. G. Greene, R. Starr, J. de Marignac, and J. Field.

2002. Deepwater habitat and fish resources associated with the Big Creek Ecological Reserve. CalCOFI. Rep. 43:120-140.

Yoklavich, M. M., M. S Love, and K. A. Forney.

2007. A fishery-independent assessment of an overfished rockfish stock, cowcod (Sebastes levis), using direct observations from an occupied submersible. Can. J. Fish. Aquat. Sci. 64:1795-1804. Article

Yoklavich, M., J. Reynolds, and D. Rosen.

2015. A comparative assessment of underwater visual survey tools: results of a workshop and user questionnaire. NOAA Tech. Memo. NMFS-TM-SWFSC-547, $44 \mathrm{p}$. 